WellBeing International

WBI Studies Repository

1996

\title{
The Effect of Substrate-Enriched and Substrate-Impoverished Housing Environments on the Diversity of Behaviour in Pigs
}

\author{
Marie Haskell \\ Scottish Agricultural College \\ Françoise Wemelsfelder \\ Scottish Agricultural College \\ Michael T. Mendl \\ Scottish Agricultural College \\ Sheena Calvert \\ Scottish Agricultural College \\ Alistair B. Lawrence \\ Scottish Agricultural College
}

Follow this and additional works at: https://www.wellbeingintlstudiesrepository.org/acwp_asie

Part of the Agribusiness Commons, Animal Studies Commons, and the Operations and Supply Chain Management Commons

\section{Recommended Citation}

Haskell, M., Wemelsfelder, F., Mendl, M. T., Calvert, S., \& Lawrence, A. B. (1996). The effect of substrateenriched and substrate-impoverished housing environments on the diversity of behaviour in pigs.

Behaviour, 133(9), 741-761.

This material is brought to you for free and open access by WellBeing International. It has been accepted for inclusion by an authorized administrator of the WBI Studies Repository. For more information, please contact wbisr-info@wellbeingintl.org.

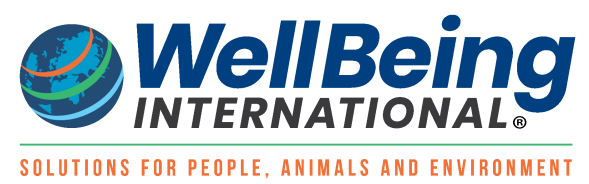




\title{
The Effect of Substrate-Enriched and Substrate- Impoverished Housing Environments on the Diversity of Behaviour in Pigs
}

\author{
Marie Haskell, Françoise Wemelsfelder, Michael T. Mendl, Sheena Calvert, and Alistair B. Lawrence \\ Scottish Agricultural College
}

\begin{abstract}
In intensive farming situations, growing animals are housed in relatively barren environments. The lack of opportunity to perform substrate-interactive and manipulative behaviour patterns may affect the expression and organization of these behaviours. However, making direct comparisons of the behaviour expressed in environments of differing physical complexity is difficult. In this experiment a relative diversity index was used to compare the behavioural repertoires of pigs housed in two different environments for a period of five months. One group of pigs (substrate-enriched) had straw, forest bark and branches added to the standard pens and the other group (substrate-impoverished) did not. The pigs were individually housed, and their behaviour was focal sampled in these pens on one day each month. It was shown that the relative diversity of manipulative behaviour shown by the pigs in the substrateimpoverished environment was lower than in the pigs in the substrate-enriched environment $(p<0.05)$. The relative diversity of the whole behavioural repertoire shown by the pigs in the substrate-impoverished environment also tended to be lower than that in the substrate-enriched environment $(p=0.06)$. It is concluded that this may be due to a difference between the two groups in motivation to interact with and manipulate objects, or a function of the manipulable quality of the substrates available to them. Alternatively, exposure to substrate-impoverished environments may interfere with the ability to express manipulative behaviour. Both situations pose a threat to the welfare of growing pigs resident in barren environments.
\end{abstract}

\section{Introduction}

In modern intensive pig farms, young growing pigs are often housed in con- ditions that are relatively barren compared with the diverse environments experienced by wild or feral pigs (e.g. Graves, 1984; Stolba \& Wood- Gush, 1989). Behaviour may be affected in a number of different ways. Behavioural problems such as tail-biting and the performance of stereotypy is thought to be partly a result of such environmentally impoverished con- ditions (Kiley-Worthington, 1977; Dantzer, 1986). It is also possible that the fundamental organization and expression of behaviour may be influ- enced by long-term exposure to relatively barren environments, especially in young animals. Long-lived animals in the wild situation need the ability to exhibit flexibility in behavioural strategy to survive, and this potential may be developed through environmental (and social) interactions during growth (Fagen, 1982). The possession of a diverse behavioural repertoire is also important in that it allows animals to employ a range of behavioural elements to interact successfully with a changing environment. It has been shown that exposure to impoverished environments can reduce the ability of animals to show complex behaviour patterns (Renner \& Rosenzweig, 1986), to employ diverse behavioural strategies to solve problems or to 
relinquish previously learned patterns of behaviour (Morgan, 1973; Mor- gan et al., 1975, 1977; Einon et al., 1978). These changes are concurrent with changes in brain structure (Renner \& Rosenzweig, 1987; Grandin et al., 1988).

There have been many studies of the effect of environmental quality on the behaviour of animals. These studies have generally compared the effect of environments containing a variety of substrates for interaction (enriched environments), with those that contain few such substrates (impoverished environments). Studies with laboratory rodents have primarily attempted to quantify the effect of the housing environment on behaviour by ex- amining differences in specific classes of behaviour, such as play (Fagen, 1982), the learning of specific operant sequences (Morgan, 1973; Morgan et al., 1975) or behaviour in open field tests (Einon \& Morgan, 1976; Einon et al., 1978; Renner \& Rosenzweig, 1986). These studies did not attempt to examine the effect of the environment on the whole behavioural repertoire of the animal. There have been experiments conducted with farm animals that have compared the effect of environmental complexity on the types of behaviour expressed (e.g. calves: Kerr \& WoodGush, 1987; pigs: Schouten, 1986; Pearce et al., 1989; Hirt \& Wechsler, 1993; Pearce \& Paterson, 1993; Beattie et al., 1994), but these studies tend not to have examined interactive behaviour in detail. These experiments show that substrate-impoverished environments influence aspects of exploratory and social behaviour. However, in all of the studies with pigs the animals were housed in groups, and an increase in the number of actions directed at pen-mates was often found in the substrate-impoverished environments. The pigs appear to have substituted an increase in social interaction or pen-mate directed activity for a lack of suitable manipulable substrates. Therefore, it is difficult to ascertain from these studies whether the rear- ing environment has an effect on the overall behavioural repertoire of the individual. So despite the obvious relevance of understanding the effect of the environment on behavioural diversity, few studies have attempted to characterize the changes in the breadth or diversity of the behavioural repertoire in any detailed way.

Information theory provides a technique for quantifying diversity and was originally developed in communication engineering to express information in quantitative terms (Losey, 1978). A parameter $\mathrm{H}$ is calculated which provides a measure of the diversity in a sequence of elements or behaviours. The greater the number of element types that occur in a section of behavioural flow, the higher the total informational variability and the value of $\mathrm{H}$ (van den Bercken \& Cools, 1980; Stolba et al., 1983). The relative diversity parameter $\mathrm{R}$ represents the number of elements observed as a proportion of the total possible repertoire in that environment. When comparing the behaviour observed in two situations that differ in environmental complexity, it is to be expected that the diversity of behaviour patterns seen will be a reflection of the environmental diversity present in the two treatments. Therefore, a direct comparison can not be particularly meaningful as the animals in the impoverished environments do not have the same opportunities to interact with substrates. A calculation of the relative diversity of observed behaviour provides a means of comparing environments differing in complexity, and is likely to be a more useful measure of the effect of the environment on behaviour.

In the work reported here we wished to examine the effect of housing environment on the expression and diversity of behaviour. To this end we compared the behaviour observed in a standard housing environment with a number of additional substrates for the pigs to interact with (substrate- enriched), with an environment in which none of these substrates were present (substrate-impoverished). Straw, forest bark and branches were chosen as the enriching substrates as they are materials that are known to encourage rooting and chewing behaviours in loose-housed pigs. The pigs were housed individually in these environments for five months, which allowed us to assess the effect of the environment alone on the diversity of behaviour and the type of behaviours performed. We also determined if rigid and relatively 
invariant behaviour patterns had developed in the pigs in the substrate-impoverished environment by examining the changes in bout lengths of behaviour over the course of the experiment.

The behaviour of each animal was sampled on one day each month. The frequencies and durations of all behaviour patterns and interactions with substrates were calculated, and the values of $H$ and $R$ determined for each observation period. Our null hypothesis was that although the pigs in the substrateenriched environment would spend more time interacting with substrates, the relative behavioural diversity would be the same for both housing conditions.

Additionally, to examine the effect of the environment on the behavioural response to novelty, a novel object was presented to each pig once a month, and the behaviour observed. The results from the latter observations will be presented in another paper (Wemelsfelder et al., in prep.).

\section{Materials and methods}

Housing and animals

The subjects of the experiment were 26 Large White Landrace crossbred female pigs, weighing between 28.0 and $45.0 \mathrm{~kg}$ (mean $=37.1 \mathrm{~kg}$ ), and around 10 weeks of age at the beginning of the experiment. The pigs were divided into the two treatment groups, with the groups balanced for weight. Each pig was housed individually in its particular treatment pen. Two experimental rooms within the same experimental house were used to house the 26 pens. The rooms were identical in terms of construction, heating and ventilation and were maintained at between 17 and $20^{\circ} \mathrm{C}$ throughout the experiment. In each room, a row of substrate-impoverished pens lay back-to-back with a row of substrate-enriched pens. There were eight pairs of pens in one room and five pairs in the other. There was a solid partition between the substrateimpoverished and substrate-enriched pens, but barred panels between all but two pens in each treatment (that had one solid and one barred panel) which allowed pigs within a treatment contact with their neighbours. All pens were $2 \times 3 \mathrm{~m}$ with a concrete floor and each contained a feed trough and a drinker bowl. Substrate-enriched pens also contained approximately $4 \mathrm{~kg}$ of straw, $5 \mathrm{~kg}$ of forest bark and two tree branches. All pigs were fed ad libitum on a diet that was appropriate to their age. They were fed at 08:30 $\mathrm{h}$ each day and the pens were cleaned at about 09:00 h. For the substrate-enriched pens this meant the removal of dirty straw and bark and the addition of new straw and bark. The substrateimpoverished pens were scraped out. The branches in the substrate-enriched pens were changed once a month.

\section{Data collection and data processing}

A focal sampling technique was used to record behaviour. The ethogram included posture, behaviour pattern and substrate at which the behaviour was directed (if any) (Table 1). The observer was seated behind a wooden screen that was placed in front of the focal animal's pen. Data were recorded using Keybehaviour (Deag, 1993) installed on an Atari Portfolio computer. No attempt was made to encourage the pigs to be active at the start of the observation period, although the first three observation periods of the day had been chosen to encompass periods when the pigs were likely to be active. One observer observed one pair of pigs at each of their four observation periods on one day. The observer recorded the behaviour of each pig in the pair for fifteen minutes before feeding, fifteen minutes after feeding, fifteen minutes after pen-cleaning and for one hour between 13:00 and 15:00 h. A Latin square design was used to balance the observation schedule over the five months of the experiment for observer and pair.

The data were processed using Keytime (Deag, 1993) to produce proportion of observation time that each behaviour was performed, rates (number of occurrences of the behaviour per minute) and mean bout lengths of behaviour. As there were many zero values present in the data which increased the level 
of non-normality, the individual behavioural elements were grouped into categories of behaviour directed at any substrate (e.g. nosing any substrate, rooting any substrate) or substrate-directed behaviours (e.g. any behaviour directed at the bars, behaviour directed at the floor). Total time spent interacting with any substrate during an observation period and total number of initiations of interaction per minute with any substrate were also calculated. Log transformation was used to increase the normality of the distribution of the data. Parametric analysis of variance was used to test the effect of treatment and month on the occurrence of the categories of behaviour that achieved normality. The analysis was blocked for the between-cell effects of pig within pair, time of day within month and observer.

TABLE 1. Definitions of postures, behavioural categories and substrates

\begin{tabular}{|c|c|}
\hline \multicolumn{2}{|l|}{ Postures: } \\
\hline Stand & Body equally supported by all four legs \\
\hline Sit & Hind-quarters on floor, fore-legs upright \\
\hline Lie on belly & Lie with sternum in contact with floor, legs under body or parallel to body \\
\hline Lie on side & $\begin{array}{l}\text { Lie with one shoulder and hip in contact with floor; legs at right-angles to lie } \\
\text { of body }\end{array}$ \\
\hline Behaviours: & (in any posture except where indicated) \\
\hline Nose & Touch or manipulate substrate with front of rooting disc \\
\hline Chew & Masticate or bit substrate other than food \\
\hline Root & Nudge or lift substrate with the top of the rooting disc \\
\hline Lick & Contact substrate with short tongue movements \\
\hline Scratch & Rub body with foot or against an object \\
\hline Drink & Ingest water \\
\hline Eat & Ingest food \\
\hline Scamper & Move rapidly in short bursts (standing only) \\
\hline Orient to observer & Look at observer \\
\hline Inactive & Perform no visible activity with mouth or snout \\
\hline Paw & Move foreleg in front-to-back motion \\
\hline Change area & Move from one quarter of the pen to another (standing only) \\
\hline $\begin{array}{l}\text { Carry/shake/pull (the pigs in the } \\
\text { substrate-enriched environment } \\
\text { only }\end{array}$ & $\begin{array}{l}\text { Hold substrate in mouth with head raised, shake head vigorously from side to } \\
\text { side with object in mouth or hold object down foot and pull upwards with } \\
\text { mouth }\end{array}$ \\
\hline \multicolumn{2}{|l|}{ Substrate: } \\
\hline Sides of pen & Solid and barred sides of pen, the gate and drinker bowl \\
\hline Food trough & Trough at front of pen \\
\hline Floor & Concrete floor without any covering of any substrate \\
\hline Neighbouring pig & Pig in next pen contacted though bars \\
\hline Non-specific substrate & $\begin{array}{l}\text { For pigs in the substrate-impoverished environment this was the mixture of } \\
\text { food and sometimes faeces on the floor; for the pigs in the substrate-enriched } \\
\text { environment it was the layer of small pieces of bark and straw closest to the } \\
\text { floor }\end{array}$ \\
\hline Straw/bark/branches & (pigs in the substrate-enriched environment only) \\
\hline
\end{tabular}


The Wilcoxon matched-pairs signed-ranks test was used to examine the effect of treat- ment, and the Friedman test for effect of month, if the data were non-normal. Although neither of these routines are able to test for interactions between treatment and month in non-normal data sets, the Friedman test can be used to provide a rough examination of the interactions. In this case, the values for one treatment were subtracted from the values for the other treatment and the Friedman test used to determine the effect of month on these differences. REML (residual maximum likelihood (Patterson \& Thompson, 1971)) procedures were used to analyse the effect of month and treatment on the bout lengths of the categories of behaviour. This analysis was used as we wished to include in the analysis only data sets in which a bout of the relevant behaviour had occurred. Therefore, although the data were transformed to have an underlying normal distribution, excluding zero values for categories of behaviour meant that the data set was unbalanced, which required the use of the REML technique. Treatment group, month and time of day were used as fixed effects and pig identity was fitted as a random effect.

To examine the diversity of the behaviour patterns performed by the pigs in the two treatment groups, a measure of diversity or information content (the parameter $\mathrm{H}$ ) and the realized diversity (the parameter $\mathrm{R}$ ) were calculated (Losey, 1978; Stolba et al., 1983). For $\mathrm{H}$ to be maximal for any period of observation, all elements of the ethogram must be observed and occur equally often. $\mathrm{R}$ is calculated by dividing $\mathrm{H}$ by Hmox, the total diversity possible within the given treatment environment. In this experiment, Hmax was lower for the substrate-impoverished environment than for the substrate-enriched environment. Diversity indices were calculated for the total repertoire of behaviours and also for the subset of manipulative behaviours. Each behaviour pattern in combination with each substrate (e.g. nose bar, chew bar, nose floor, lick floor, etc.) was used as an element in the analysis. The behaviour patterns included in the manipulative behaviour index were chew, nose, root, carry/shake/pull, lick and paw. R was calculated for each observation period, and these values were checked for normality of distribution and analysed for the effects of treatment and month using repeated measures ANOVA as above.

\section{Results}

Measures of behavioural diversity

When the whole behavioural repertoire was considered, the pigs in the substrate-enriched pens had higher values of $H$ (total diversity index) $\left(F_{1,12}=22.15, p<0.001\right)$ than the pigs in the substrateimpoverished environment. Pigs in the substrate-enriched pens also tended to have higher $R$ (relative diversity index) values than the pigs in the substrate- impoverished environment $\left(F_{1,12}=4.48, p=0.06\right)$, indicating that these pigs tended to perform more of their total repertoire of behaviour than pigs in the substrate-impoverished pens. When only manipulative behaviour patterns were considered, the pigs in the substrate-enriched pens again had higher $\mathrm{H}$ values $\left(F_{1,12}=28.02, p<0.001\right)$ and had significantly higher values of $R$ than the pigs in the substrate-impoverished pens $\left(F_{1,12}=6.07, p<0.05\right)$.

There was a significant effect of month on both the $H$ and $R$ values for manipulative behaviour. The values increased until the third month and then fell away to below the level of the first month (for both: $F_{4,48}=2.70, p<0.05$; Fig. 1). There were no month effects on $H$ or $R$ when all behaviours were considered, and there were no interactions between treatment and month for either the whole behavioural repertoire or for the sub-set of manipulative behaviours.

\section{Effect of treatment on posture}

Although there was no difference between the treatments in the proportion of time spent standing, sitting or lying on belly ( $p>0.05$ for all), the pigs in the substrate-enriched pens had higher rates of these behaviours (rate of standing: $F_{1,12}=28.97, p<0.001$; rate of sitting: $F_{1,12}=5.80, p<0.05$; rate of lying on 
belly: $F_{1,12}=4.94, p<0.05$ ), indicating that they changed posture more often than the pigs in the substrate-impoverished pens. Pigs in the substrate-impoverished environment had longer bouts of lying on belly $\left(W_{1}=5.7, p<0.05\right)$, but there was no difference between the treatments in the bout lengths spent in any of the other postures $(p>0.05$ for all). There was no difference between the treatments in the time spent lying on side $\left(F_{1,12}=0.04 ; p>0.05\right)$ and no difference between the treatments in the rate of this behaviour $\left(F_{1,12}=0.63 ; p>0.05\right)$.

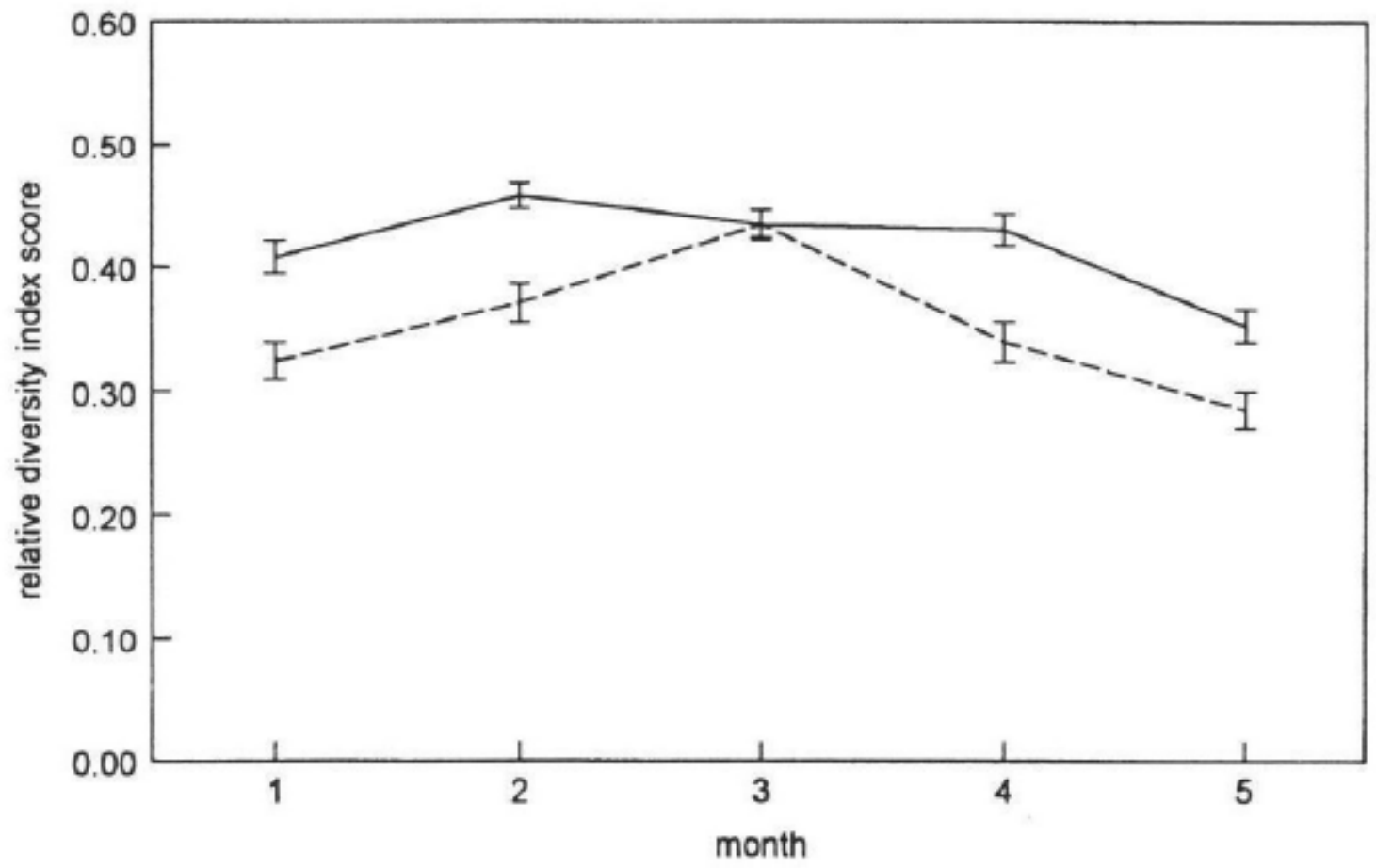

Fig. 1. Graph showing the mean values of $R$ (relative diversity) for manipulative behaviour across the five months of the experiment for the substrate-enriched (continuous line) and substrate-impoverished (broken line) pigs.

\section{Effect of treatment on behavior}

The housing environment had a significant effect on a number of behaviour patterns and the general activity of the pigs. Pigs housed in the substrate- enriched pens spent longer in total interacting with the available substrates $\left(F_{1,12}=28.77, p<0.001\right)$, initiated more bouts of interaction with those substrates $\left(F_{1,12}=5.26, p<0.05\right)$ and had longer total bouts of interaction with substrates $\left(F_{1,12}=24.01, p<0.001\right)$. The pigs in the substrate- enriched pens spent longer scampering and had a higher rate of scampering than the pigs in the substrate-impoverished pens (proportion of time: $F_{1,12}=6.14, p<0.05$; rate: $F_{1,12}=$ 6.13, $p<0.05$ ), and moved between areas of the pen more frequently (rate: $F_{1,12}=10.50, p<0.01$ ). There was an effect of treatment on the type of behaviour performed, the particular substrate that it was directed at and the bout lengths of these interactions (Tables 2-4). The pigs housed in the substrateenriched pens spent a larger proportion of time rooting $\left(Z_{12}=5.0, p<0.01\right)$, chewing $\left(Z_{13}=0.0, p<0.01\right)$ and nosing $\left(F_{1,12}=8.97, p<0.05\right)$. They also had higher rates of rooting $\left(Z_{12}=2.0, p<0.01\right)$, chewing 
$\left(F_{1,12}=26.68, p<0.001\right)$ and nosing $\left(F_{1,12}=9.68, p<0.01\right)$, had longer bouts of chewing $\left(W_{1}=35.6, p<\right.$ $0.001)$ and had a higher rate of pawing $\left(F_{1,12}=12.75, p<0.01\right)$. Much of this chewing and nosing performed by the pigs in the substrate- enriched environment was directed at the straw, bark and the mixture of the two on the floor of the pen (non-specific substrate) (Table 5). Although the total amount of rooting performed appears to be much less than re- ported elsewhere for young pigs (Wood-Gush \& Beilharz, 1983; Appleby \& Wood-Gush, 1988), both the categories of 'nosing' and 'rooting' in the present paper would have been described as 'rooting' in these studies. Pigs in the substrate-enriched pens had a higher rate of drinking $\left(F_{1,12}=9.29, p<0.05\right)$ and tended to spend longer drinking $\left(F_{1,12}=4.64, p=\right.$ $0.052)$, but the pigs in the substrate-impoverished environment had longer bouts of drinking $\left(W_{1}=5.8, p<\right.$ $0.05)$.

TABLE 2. Effect of treatment on the proportion of time spent performing the various categories of behaviour and the rate (mean number of times per minute) that the behaviour was initiated

\begin{tabular}{|c|c|c|c|}
\hline Behaviour & Substrate-enriched & $\begin{array}{c}\text { Substrate- } \\
\text { impoverished }\end{array}$ & Significance \\
\hline \multicolumn{4}{|c|}{ Proportion (of observation period): } \\
\hline Interact with any substrate & $0.448 \pm 0.015$ & $0.239 \pm 0.010$ & $p<0.001$ \\
\hline Root & $0.0059 \pm 0.0015$ & $0.0005 \pm 0.0003$ & $p<0.01$ \\
\hline Chew & $0.2124 \pm 0.0129$ & $0.0451 \pm 0.0005$ & $p<0.001$ \\
\hline Nose & $0.2257 \pm 0.0120$ & $0.1711 \pm 0.0115$ & $p<0.05$ \\
\hline Lick & $0.0024 \pm 0.0008$ & $0.0086 \pm 0.0014$ & $p<0.001$ \\
\hline Scamper & $0.00092 \pm 0.00027$ & $0.00035 \pm 0.00016$ & $p<0.05$ \\
\hline Drink & $0.0130 \pm 0.0017$ & $0.0090 \pm 0.0010$ & $p=0.52$ \\
\hline Chew with nothing in mouth & $0.0001 \pm 0.000006$ & $0.0123 \pm 0.0032$ & $p<0.001$ \\
\hline Inactive & $0.453 \pm 0.022$ & $0.663 \pm 0.019$ & $p<0.01$ \\
\hline Scratch & $0.0039 \pm 0.0009$ & $0.0017 \pm 0.0004$ & $p<0.08$ \\
\hline Orient towards observer & $0.0018 \pm 0.0005$ & $0.0022 \pm 0.0005$ & NS \\
\hline Stand & $0.325 \pm 0.018$ & $0.268 \pm 0.019$ & NS \\
\hline Sit & $0.0262 \pm 0.004$ & $0.0241 \pm 0.006$ & NS \\
\hline Lie belly & $0.457 \pm 0.017$ & $0.523 \pm 0.021$ & NS \\
\hline Lie side & $0.192 \pm 0.018$ & $0.185 \pm 0.018$ & NS \\
\hline \multicolumn{4}{|c|}{ Rate (no. of occurences of the behavior per minute): } \\
\hline Interact with any substrate & $0.498 \pm 0.020$ & $0.485 \pm 0.023$ & $p<0.05$ \\
\hline Root & $0.0231 \pm 0.0042$ & $0.0025 \pm 0.0009$ & $p<0.001$ \\
\hline Chew & $0.413 \pm 0.024$ & $0.212 \pm 0.019$ & $p<0.001$ \\
\hline Nose & $0.694 \pm 0.037$ & $0.551 \pm 0.038$ & $p<0.01$ \\
\hline Lick & $0.0099 \pm 0.0026$ & $0.0375 \pm 0.0050$ & $p<0.001$ \\
\hline Paw & $0.0210 \pm 0.0055$ & $0.0053 \pm 0.0019$ & $p<0.01$ \\
\hline Scamper & $0.0075 \pm 0.0018$ & $0.0035 \pm 0.0016$ & $p<0.05$ \\
\hline Change area & $0.320 \pm 0.020$ & $0.215 \pm 0.017$ & $p<0.01$ \\
\hline Drink & $0.0446 \pm 0.0038$ & $0.0258 \pm 0.0027$ & $p<0.05$ \\
\hline Chew with nothing in mouth & $0.0006 \pm 0.0003$ & $0.0375 \pm 0.0084$ & $p<0.001$ \\
\hline Inactive & $0.468 \pm 0.028$ & $0.500 \pm 0.033$ & NS \\
\hline Scratch & $0.0278 \pm 0.0049$ & $0.0161 \pm 0.0036$ & $p=0.07$ \\
\hline Orient towards observer & $0.0125 \pm 0.0026$ & $0.0155 \pm 0.0031$ & NS \\
\hline Stand & $0.0763 \pm 0.0037$ & $0.0528 \pm 0.0035$ & $p<0.001$ \\
\hline Sit & $0.0399 \pm 0.0037$ & $0.0217 \pm 0.0029$ & $p<0.05$ \\
\hline Lie belly & $0.0974 \pm 0.0042$ & $0.0837 \pm 0.0040$ & $p<0.05$ \\
\hline Lie side & $0.0335 \pm 0.0027$ & $0.0268 \pm 0.002$ & NS \\
\hline
\end{tabular}

The data presented are grand means across all five months and SEMs. 
TABLE 3. Effect of treatment on the proportion of time spent interacting with the various substrates and the rate (mean number of times per minute) that the interaction with that substrate was initiated

\begin{tabular}{|lccc|}
\hline & Substrate-enriched & Substrate-impoverished & Significance \\
\hline Proportion (of observation period): & & & \\
Floor-directed & $0.0058 \pm 0.0012$ & $0.0992 \pm 0.0079$ & $p<0.001$ \\
Feeder-directed & $0.0040 \pm 0.0007$ & $0.0105 \pm 0.0019$ & $p<0.05$ \\
Pen-directed & $0.0308 \pm 0.0033$ & $0.0455 \pm 0.0040$ & $p<0.05$ \\
Neighbour-directed & $0.0114 \pm 0.0015$ & $0.0186 \pm 0.0030$ & $\mathrm{NS}$ \\
Non-specific substrate-directed & $0.0823 \pm 0.0086$ & $0.0450 \pm 0.0055$ & $p<0.05$ \\
Straw-directed & $0.168 \pm 0.012$ & $\mathrm{NA}$ & \\
Bark-directed & $0.138 \pm 0.013$ & $\mathrm{NA}$ & \\
Branch-directed & $0.0069 \pm 0.0016$ & $\mathrm{NA}$ & $\mathrm{NS}$ \\
\hline Rate (per minute): & & & $\mathrm{NS}$ \\
Floor-directed & $0.025 \pm 0.005$ & $0.341 \pm 0.024$ & $\mathrm{NS}$ \\
Feeder-directed & $0.0372 \pm 0.0045$ & $0.0592 \pm 0.0077$ & $\mathrm{NS}$ \\
Pen-directed & $0.197 \pm 0.016$ & $0.245 \pm 0.021$ & \\
Neighbour-directed & $0.0678 \pm 0.0070$ & $0.0764 \pm 0.0085$ & \\
Non-specific substrate-directed & $0.214 \pm 0.020$ & $0.165 \pm 0.019$ & \\
Straw-directed & $0.303 \pm 0.017$ & $\mathrm{NA}$ & \\
Bark-directed & $0.218 \pm 0.018$ & $\mathrm{NA}$ & $\mathrm{NA}$ \\
Branch-directed & $0.0106 \pm 0.0017$ & $\mathrm{NA}$ & \\
\hline
\end{tabular}

The data presented are grand means across all five months and SEMs.

\section{Effect of treatment on substrate interactions}

There were also differences between the treatments in the substrates interacted with. The pigs in the substrate-impoverished pens spent longer interacting with the floor $\left(Z_{13}=0.0, p<0.01\right)$, the sides of the pen $\left(Z_{13}=16.00, p<0.05\right)$ and the feed trough $\left(Z_{13}=13.00, p<0.05\right)$, and had a greater rate of interaction with the floor $\left(Z_{13}=0.0, p<0.01\right)$. The bout lengths of interaction with the sides of the pen $\left(W_{1}\right.$ $=11.9, p<0.005)$ and the feed trough $\left(W_{1}=5.8, p<0.05\right)$ were also longer for the pigs in the substrateimpoverished environment. Pigs in the substrate- impoverished pens spent longer chewing with nothing in the mouth $\left(Z_{13}=0.0, p<0.01\right)$, had a higher rate of this behaviour $\left(Z_{13}=0.0, p<0.01\right)$ and performed longer bouts of it $\left(W_{1}=5.8, p<0.05\right)$ than the pigs in the substrate-enriched environment. These pigs also had longer bouts of behaviour directed at the pig in the neighbouring pen $\left(W_{1}=8.4, p<0.005\right)$. The pigs in the substrate-enriched environment interacted more with the non-specific substrate on the floor of the pen $\left(F_{1,12}=6.20, p<0.05\right)$ and had longer bouts of interaction with this substrate $\left(W_{1}=9.4, p<\right.$ $0.005)$.

\section{Effect of month on posture}

The proportion of time spent sitting $\left(F_{4,48}=3.44, p<0.05\right)$ and rate of sitting fell over the course of the experiment $\left(F_{4,48}=4.43, p<0.01\right)$, as did the proportion of time spent lying on belly $\left(F_{4,48}=3.21, p<\right.$ $0.05)$ and rate of occurrence of lying on belly $\left(F_{4,48}=4.10, p<0.01\right)$. The rate of standing also fell with increasing time $\left(F_{4,48}=4.05, p<0.01\right)$, but both the bout lengths of standing $\left(W_{4}=36.7, p<0.001\right)$ and lying on side $\left(W_{4}=10.8, p<0.05\right)$ increased over the months. 
TABLE 4. The effect of treatment on the bout length(s) of the various behavioural categories and substratedirected categories

\begin{tabular}{|lccc|}
\hline Mean bout length(s) & $\begin{array}{c}\text { Substrate- } \\
\text { enriched }\end{array}$ & $\begin{array}{c}\text { Substrate- } \\
\text { impoverished }\end{array}$ & Significance \\
\hline Interact with substrates (i.e. one or more substrates & $70.75 \pm 4.84$ & $33.4 \pm 2.68$ & $p<0.001$ \\
consecutively) & $11.27 \pm 1.37$ & $20.15 \pm 7.17$ & NS \\
Root & $43.67 \pm 4.46$ & $15.15 \pm 1.28$ & $p<0.001$ \\
Chew & $22.48 \pm 1.08$ & $22.10 \pm 1.36$ & NS \\
Nose & $12.47 \pm 2.11$ & $13.02 \pm 1.42$ & NS \\
Lick & $7.52 \pm 1.47$ & $6.61 \pm 1.22$ & NS \\
Scamper & $18.07 \pm 1.41$ & $22.91 \pm 1.68$ & $p<0.05$ \\
Drink & $4.44 \pm 1.88$ & $21.07 \pm 4.53$ & $p<0.05$ \\
Chew with nothing in mouth & $205.4 \pm 23.86$ & $325.2 \pm 29.66$ & $p<0.001$ \\
Inactive & $309.5 \pm 17.68$ & $395.4 \pm 30.15$ & $N S$ \\
Stand & $36.47 \pm 4.63$ & $64.4 \pm 16.12$ & $N S$ \\
Sit & $371.3 \pm 20.27$ & $513.2 \pm 29.50$ & $p<0.005$ \\
Lie belly & $483.8 \pm 50.79$ & $571.9 \pm 53.14$ & $N S$ \\
Lie side & $15.09 \pm 1.78$ & $18.06 \pm 1.20$ & $N S$ \\
Floor-directed & $6.68 \pm 0.81$ & $9.25 \pm 0.99$ & $p<0.05$ \\
Feeder-directed & $9.27 \pm 0.68$ & $11.87 \pm 0.64$ & $p<0.001$ \\
Pen-directed & $9.53 \pm 0.68$ & $13.69 \pm 1.35$ & $p<0.01$ \\
Neighbour-directed & $26.89 \pm 6.60$ & $16.06 \pm 2.40$ & $p<0.01$ \\
Non-specific substrate-directed & $40.50 \pm 3.81$ & $\mathrm{~N} / \mathrm{A}$ & \\
Straw & $39.86 \pm 7.52$ & $\mathrm{~N} / \mathrm{A}$ & \\
Bark & $15.04 \pm 1.38$ & $\mathrm{~N} / \mathrm{A}$ & \\
Branches & & & \\
\hline
\end{tabular}

Data presented are grand means across all five months and SEMs

\section{Effect of month on behavior}

A number of the behavioural measurements changed over the course of the experiment (Table 6). The proportion of time the pigs spent orienting towards the observer decreased with time $\left(F_{4,48}=7.93, p<\right.$ $0.001)$ as did the rate of this behaviour $\left(F_{4,48}=8.75, p<0.001\right)$ indicating that the pigs became increasingly habituated to the presence of an observer as the experiment progressed. The proportion of time spent scampering $\left(F_{4,48}=3.41, p<0.05\right)$ and the rate of scampering $\left(F_{4,48}=3.84, p<0.01\right)$ fell as the experiment progressed.

The bout length of chewing substrates $\left(W_{4}=9.9, p<0.05\right)$ showed a general increase over the course of the experiment, while time spent nosing $\left(W_{4}=10.0, p<0.05\right)$ rose between the first and second month and then fell to a more consistent level. Time spent licking substrates $\left(F_{4,48}=3.31, p<0.05\right)$, rate of licking $\left(F_{4,48}=3.02, p<0.05\right)$ and mean bout length of licking $\left(W_{4}=14.9, p<0.005\right)$ all declined over the experiment. However, the proportion of time spent chewing with nothing in the mouth $\left(S_{4}=13.60, p<\right.$ $0.01)$ and the rate of this behaviour $\left(S_{4}=10.90, p<0.05\right)$ both increased with time.

Time spent drinking $\left(F_{4,48}=3.40, p<0.05\right)$, rate of drinking $\left(F_{4,48}=2.62, p<0.05\right)$ and mean bout length of drinking $\left(W_{4}=17.1, p<0.005\right)$ all increased with time, perhaps reflecting an increase in demand 
relative to increasing body size. The pigs performed less scratching behavior $\left(F_{4,48}=6.70, p<0.001\right)$, and at a lower rate $\left(F_{4,48}=8.57, p<0.001\right)$, with increasing time.

TABLE 5. Proportion of time the pigs in the substrate-enriched environment spent interacting with straw, bark, branches and the mixed substrate on the floor

\begin{tabular}{|lll|}
\hline Chew & Straw & $0.0734 \pm 0.0090$ \\
& Bark & $0.0833 \pm 0.0092$ \\
& Branches & $0.0033 \pm 0.0011$ \\
& Non-specific substrate & $0.0479 \pm 0.0065$ \\
\hline Nose & $0.0899 \pm 0.0069$ \\
& Straw & $0.0531 \pm 0.0058$ \\
& Bark & $0.0034 \pm 0.0006$ \\
& Branches & $0.0341 \pm 0.0033$ \\
\hline
\end{tabular}

The data presented are grand means across all five months and SEMs.

\section{Effect of month on substrate interactions}

The bout length of interaction with the feed trough increased until the fourth month and then fell $\left(W_{4}=5.8\right.$, $p<0.05)$ and the bout length of interaction with non-specific substrates on the floor rose to month 2 and then fell thereafter $\left(W_{4}=14.9, p<0.005\right)$. Pigs in the substrate-enriched environment had a decreasing rate of interaction with the branches with increasing month $\left(F_{4,48}=5.05, p<0.01\right)$ and also tended to initiate interactions with the straw less frequently $\left(F_{4,48}=2.20, p=0.083\right)$. However, the bout length of interaction with straw increased $\left(W_{4}=10.2, p<0.05\right)$.

\section{Month by treatment effects}

One of the features of this experiment was scarcity of month by treatment interactions, indicating that neither treatment had an increasing or decreasing effect on behaviour relative to the other over the course of the experiment. There was a significant month by treatment interaction for proportion of time spent scratching the body $\left(F_{4,48}=3.85, p<0.01\right)$ and rate of scratching $\left(F_{4,48}=5.71, p<0.01\right)$. The rate $\left(F_{4,48}=2.65, p<0.05\right)$ and proportion of time $\left(F_{4,48}=2.72, p<0.05\right)$ spent lying on belly also showed a month by treatment interaction. The proportion of time spent lying on belly was higher in pigs in the substrate-impoverished pens, except for the second month, while the rate of lying on belly was higher for pigs in the substrate-enriched pens except for the third month.

When the Friedman test was used to examine the effect of month on the difference between the two treatments in proportion of time spent chewing with nothing in the mouth, a significant interaction between treatment and month was found $\left(S_{4}=11.38, p<0.05\right)$. It showed that the pigs in the substrateimpoverished environment always performed more of this behaviour pattern, but that the increase with month was more pronounced in the pigs in the substrate-impoverished environment.

\section{Effects of treatment on liveweight gain}

There was no difference between the two treatment groups in weight at the end of the trial $\left(F_{1,24}=0.34\right.$, $p>0.05$; means and standard errors for substrate-enriched environment vs substrate-impoverished environment: $144.38 \pm 3.87 \mathrm{~kg}$ vs $141.23 \pm 3.81 \mathrm{~kg}$ ). 
TABLE 6. The effect of month on the mean proportion of time spent performing the various behavioural categories or category of substrate-directed behaviour, the mean number of times the behaviour was performed per minute, and the mean bout length

\begin{tabular}{|c|c|c|c|c|c|c|c|}
\hline & Month 1 & Month 2 & Month 3 & Month 4 & Month 5 & SEM & Significance \\
\hline \multicolumn{8}{|l|}{ Proportion (of observation period): } \\
\hline Lick & 0.00606 & 0.01130 & 0.00674 & 0.00219 & 0.00119 & 0.00082 & $p<0.05$ \\
\hline Scratch & 0.00636 & 0.00272 & 0.00254 & 0.00179 & 0.00051 & 0.00048 & $p<0.001$ \\
\hline Orient to observer & 0.00403 & 0.00192 & 0.00387 & 0.00012 & 0.00002 & 0.00035 & $p<0.001$ \\
\hline Drink & 0.00559 & 0.00928 & 0.01073 & 0.01623 & 0.01319 & 0.00104 & $p<0.05$ \\
\hline Scamper & 0.00113 & 0.00057 & 0.00113 & 0.00030 & 0.00005 & 0.00016 & $p<0.05$ \\
\hline Chew with nothing in the mouth & 0.0028 & 0.0002 & 0.0063 & 0.0097 & 0.0127 & 0.0016 & $p<0.05$ \\
\hline Lie belly & 0.553 & 0.452 & 0.513 & 0.472 & 0.460 & 0.014 & $p<0.05$ \\
\hline Sit & 0.0368 & 0.0286 & 0.0203 & 0.0231 & 0.0168 & 0.0036 & $p<0.05$ \\
\hline \multicolumn{8}{|l|}{ Rate (no. of occurrences/min): } \\
\hline Lick & 0.0272 & 0.0334 & 0.0351 & 0.0163 & 0.0064 & 0.0029 & $p<0.05$ \\
\hline Scratch & 0.0474 & 0.0268 & 0.0165 & 0.0147 & 0.0042 & 0.0031 & $p<0.001$ \\
\hline Orient to observer & 0.0401 & 0.0130 & 0.0141 & 0.0016 & 0.0013 & 0.0020 & $p<0.001$ \\
\hline Drink & 0.0240 & 0.0380 & 0.0450 & 0.0377 & 0.0314 & 0.0024 & $p<0.05$ \\
\hline Scamper & 0.0125 & 0.0056 & 0.0059 & 0.0026 & 0.0008 & 0.0012 & $p<0.01$ \\
\hline Lie belly & 0.1114 & 0.0890 & 0.1016 & 0.0813 & 0.0694 & 0.0029 & $p<0.01$ \\
\hline Sit & 0.0513 & 0.0362 & 0.0322 & 0.0186 & 0.0157 & 0.0024 & $p<0.01$ \\
\hline Stand & 0.0813 & 0.0747 & 0.0660 & 0.0563 & 0.0446 & 0.0026 & $p<0.01$ \\
\hline $\begin{array}{l}\text { Straw-directed behavior } \\
\text { (substrate-enriched only) }\end{array}$ & 0.392 & 0.342 & 0.296 & 0.252 & 0.231 & 0.01 & $p=0.08$ \\
\hline Branch-directed behavior & 0.0260 & 0.0077 & 0.0051 & 0.0112 & 0.0029 & 0.0009 & $p<0.01$ \\
\hline \multicolumn{8}{|l|}{ Mean bout length(s) } \\
\hline Chew & 18.91 & 31.52 & 27.03 & 38.69 & 42.40 & 2.69 & $p<0.05$ \\
\hline Nose & 18.16 & 25.15 & 23.14 & 21.35 & 23.47 & 0.86 & $p<0.05$ \\
\hline Lick & 12.92 & 19.85 & 12.12 & 7.30 & 11.09 & 1.20 & $p<0.01$ \\
\hline Drink & 15.78 & 14.24 & 18.06 & 24.73 & 26.42 & 1.09 & $p<0.01$ \\
\hline Stand & 267.6 & 348.7 & 298.1 & 387.2 & 466.8 & 16.96 & $p<0.001$ \\
\hline Lie side & 433.4 & 552.6 & 471.2 & 571.5 & 596.4 & 11.62 & $p<0.05$ \\
\hline Feed trough-directed behaviour & 5.79 & 8.93 & 9.13 & 10.19 & 5.47 & 0.64 & $p<0.05$ \\
\hline Non-specific substrate-directed behaviour & 15.74 & 29.64 & 20.07 & 24.87 & 18.51 & 1.71 & $p<0.01$ \\
\hline $\begin{array}{l}\text { Straw-directed behaviour } \\
\text { (substrate-enriched only) }\end{array}$ & 24.90 & 39.93 & 49.06 & 39.72 & 48.87 & 3.81 & $p<0.05$ \\
\hline
\end{tabular}

Only the significant results have been presented.

\section{Discussion}

The effect of the substrate-impoverished housing environment in this experiment was to reduce the relative diversity of manipulative behaviours, and to a smaller extent reduce the relative diversity of behaviour shown in the whole behavioural repertoire, compared with the substrate-enriched environment. This indicates that the observed reduction in manipulative behaviour in the substrate-impoverished 
environment is not solely due to the fewer numbers of substrates, but suggests that the housing environment had affected the tendency to express this type of behaviour. This result is similar to that of the study by Hirt \& Wechsler (1993) who reported that the diversity of 'exploratory/manipulative behaviour' was higher in their enriched pens. However, in their study the behavioural categories used were broad enough so that each of them could be observed in all environments. Since $H_{\max }$ was the same for all three of the test environments, values of $H$ and $R$ would have been the same, so only $H$ (overall diversity) was calculated. We believe that including all possible combinations of behaviour and substrate as elements in a calculation of relative diversity, as done in this paper, provided a more rigorous test of the effect of housing environment, as all possible interactions with the environment were included.

There are two possible explanations for the differences in behaviour between the two environments. Firstly, there may have been a difference between the two groups of pigs in their motivation to interact with and manipulate objects, which may have been a result of the differences in the manipulable quality of the substrates available to them. The behaviour patterns that were performed by the pigs in the substrateenriched environment most frequently and for longest were nosing and chewing, and the preferred substrate for this was straw, bark, and the mixture of the two on the floor. In the substrate-impoverished environment where these substrates were not available, the pigs performed less chewing and nosing, and also rooting of substrates, but performed more licking behaviour. The greater level of substrate-interaction in the substrate-enriched environment may have encouraged more active behaviour, as the pigs in this environment moved about, and changed posture, more often. It is likely that the rather fixed and rigid substrates available to the pigs in the substrate- impoverished environment did not encourage the performance of chewing and nosing. However, the pigs in the substrate-impoverished environment performed more licking and chewing with nothing in the mouth. This suggests that the motivation to perform manipulative oral behaviour in growing pigs may have an endogenous component, but that it is strongly influenced by the manipulable quality of the substrates available. In studies in which the animals were housed in groups, the pen-mates may have been the substrates with the most manipulable quality (e.g. Schouten, 1986; Beattie et al., 1994).

An alternative explanation is that the substrate-impoverished environment had a fundamental effect on the organization and expression of interactive behaviour in the resident pigs. The lack of opportunity to perform manipulative behaviour may have affected the animal's ability to perform this type of behaviour in the long term in any context. Especially in growing pigs, such as in this experiment, the opportunity to express manipulative behaviour or play while young may have longer-term effects on the appropriate expression of behaviour in the older animal. It has also been suggested in studies with rats that the standard barren laboratory conditions may be inadequate to develop a full behavioural repertoire; in particular those behaviours associated with exploratory manipulation and play (Fagen, 1982). The consequences for the long-term welfare of pigs housed in environments that do not allow the full expression of the behavioural repertoire remains to be examined. This issue will be examined further in another paper (Wemelsfelder et al., in prep.).

The pigs housed in the substrate-impoverished housing environment tended to have a smaller behavioural repertoire than those housed in the substrate-enriched environment. It has been shown in rats that the effects of social isolation are dependent on the time at which the isolation period occurs, relative to the time at which social behaviour develops. Rats isolated prior to this socialization period differ from controls in their interaction with objects and in their activity in the open field, while rats isolated after this period do not differ from socially reared rats in these measures (Einon, 1980). The period in which social behaviour develops in young pigs is between 2 and 6 weeks of age (Newberry \& Wood-Gush, 1988). It is possible that effect of the housing environment on the whole behavioural repertoire may have been greater if the trial had begun before this socialization period. 
The substrate-impoverished environment did not appear to markedly affect the rigidity of behaviour, nor the ability to switch between behaviour patterns, as pigs in this environment did not have consistently longer or smaller bouts lengths compared with the pigs in the substrate-enriched environment, a conclusion similar to that made by Kerr \& Wood-Gush (1987). The rate of initiation of bouts of behaviour and the bout lengths of interaction with the substrates largely reflected the proportion of time spent performing the behaviour or interacting with the substrate. However, the higher rate of vacuum chewing shown by the pigs in the substrate- impoverished environment and the overall increase in chewing across the experiment in all pigs might indicate that some persistent oral behaviours had developed.

The rigidity or flexibility of behaviour would be examined more effectively by comparing the variability in sequences of behaviour between the two environments. Stolba et al. (1983) calculated $H$ and $R$ values in an attempt to characterize the rigidity and predictability of behavioural sequences evident in stereotypy. However, as these measures of diversity do not take into account the order in which the different elements occur, they would only provide a very crude estimate of rigidity or predictability.

An unexpected outcome of this experiment is the marked lack of month by treatment interactions and overall month effects on manipulative behaviours. The substrate-impoverished environment did not seem to have an increasing effect on behaviour relative to the substrate-enriched environment over time. This may mean that the effects of the two environments were present from the first observation, or that the treatments were not dissimilar enough to create this effect. It may also be an effect of the age of the pigs at the start of the experiment as discussed earlier. Many of the significant effects of month on behaviour, such as decreased time spent scampering, sitting and lying on belly, and increased drinking may have been due to maturation. A decrease in the rates of standing, sitting and lying on belly indicates that the pigs made fewer changes of posture, although time spent standing remained the same. All pigs appear to have been the most active in the second month of observation as time spent standing and scampering are highest in this month. This may also be a maturational effect, as the pigs were quite small when first put into the trial, and scampering may appear only within a limited period during the growth of the pig.

In conclusion, it appears that the substrate-impoverished housing conditions caused a reduction in the diversity of manipulative behaviour compared with the substrate-enriched environment. This may be due to a de- creased motivation to perform these behaviours because of the paucity of suitable substrates, or because of a more profound effect of the substrate- impoverished environment on the development and expression of behaviour. In either case the welfare of the animal may be at risk because of the inability to express motivated behaviour or because of a degradation of the behavioural repertoire.

\section{Acknowledgments}

We are very grateful to Lesley Deans for assisting with the observations, to Joan Chirnside and Kirsty McLean for taking care of the animals, and to David Hitchcock of BIOSS for statistical advice. The project was funded by the BBSRC of the UK and the Scottish Office Agriculture, Environment and Fisheries Department. FW was personally supported by the Netherlands Organization for Scientific Research.

\section{References}

Appleby, M.C. \& Wood-Gush, D.G.M. (1988). Effect of earth as an additional stimulus on the behaviour of confined piglets. - Behav. Proc. 17, p. 83-91. 
Beattie, V.E., Walker, N. \& Sneddon, I.A. (1994). Effects of early environment on the subsequent behaviour of the pig. - In: Proceedings of the British Society of Animal Production. Winter Meeting, 1994.

van den Bercken, J.H.L. \& Cools, A.R. (1980). Information-statistical analysis of social interaction and communication: an analysis-of-variance approach. - Anim. Behav. 28, p. 172-188.

Dantzer, R. (1986). Behavioral, physiological and functional aspects of stereotyped behavior : a review and a re-interpretation. - J. Anim. Sci. 62, p. 1776-1786.

Deag, J.M. (1993). Keytime: a program system for recording and analysing behavioural data. - Copyright John M. Deag 1987-1993, 10 Fletcher Grove, Penicuik, Midlothian, UK.

Einon, D. (1980). Environmental influences and exploration in the rat. - Appl. Anim. Ethol. 6, p. 384.

-- \& Morgan, M. (1976). Habituation of object contact in socially-reared and isolated rats (Rattus norvegicus). - Anim. Behav. 24, p. 415-420.

--, Morgan, M.J. \& Kibbler, C.C. (1978). Brief periods of socialization and later behaviour in the rat. - Dev. Psychobiol. 11, p. 213-225.

Fagen, R. (1982). Evolutionary issues in development of behavioural flexibility. - In: Perspectives in ethology. Vol. 5. (P.P.G. Bateson \& P.H. Klopfer, eds). Plenum Press, New York.

Grandin, T., Curtis, S.E. \& Greenough, W.T. (1988). Environmental enrichment for pigs: differences in somatosensory cortical neurons and subsequent behaviour. - Proceedings of the Animal Hygiene Conference, Skara, Sweden.

Graves, H.B. (1984). Behavior and ecology of wild and feral swine (Sus scrofa). - J. Anim. Sci. 58, p. 482492.

Hirt, H. \& Wechsler, B. (1993). Behavioural diversity as a measure of welfare: A study in pigs. Proceedings of the 27th International Conference of the ISAE, Berlin, Germany.

Kerr, S.G.C. \& Wood-Gush, D.G.M. (1987). A comparison of the early behaviour of inten- sively and extensively reared calves. - Anim. Prod. 45, p. 181-190.

Kiley-Worthington, M. (1977). Behavioural problems of farm animals. - Oriel Press, Stocksfield, Great Britain.

Losey, G.S. (1978). Information theory and communication. - In: Quantitative ethology (P.W. Colgan, ed.). John Wiley and Sons, New York.

Morgan, M.J. (1973). Effects of post-weaning environment on learning in the rat. - Anim. Behav. 21, p. 429-442.

--, Einon, D.F. \& Nicholas, D. (1975). The effects of isolation rearing on behavioural inhibition in the rat. Q. J. Exp. Psychol. 27, p. 615-634.

--, -- \& Morris, R.G.M. (1977). Inhibition and isolation in the rat: extinction and satiation. - Physiol. Behav. 18, p. 1-5.

Newberry, R.C. \& Wood-Gush, D.G.M. (1988). Development of some behaviour patterns in piglets under semi-natural conditions. - Anim. Prod. 46, p. 103-109.

Patterson, H.D. \& Thompson, R. (1971). Recovery of inter-block information when block sizes are unequal. - Biometrika 58, p. 545-554.

Pearce, G.P., Paterson, A.M. \& Pearce, A.N. (1989). The influence of pleasant and unpleas- ant handling and the provision of toys on the growth and behaviour of male pigs. - Appl. Anim. Behav. Sci. 23, p. 27-37.

-- \& Paterson, A.M. (1993). The effect of space restriction and provision of toys during rearing on the behaviour, productivity and physiology of male pigs. - Appl. Anim. Behav. Sci. 36, p. 11-28.

Renner, M.J. \& Rosenzweig, M.R. (1986). Object interactions in juvenile rats (Rattus norvegicus): effects of different experiential histories. - J. Comp. Physiol. Psychol. 100, p. 229-236.

- - \& - - (1987). Enriched and impoverished environments: effects on brain and behavior. - SpringerVerlag, New York. 
Schouten, W.P.G. (1986). Rearing conditions and behaviour in pigs. - PhD thesis, Univer- sity of Wageningen, the Netherlands.

Stolba, A., Baker, N. \& Wood-Gush, D.G.M. (1983). The characterization of stereo- typed behaviour in stalled sows by informational redundancy. - Behaviour 87, p. 157-182.

-- \& Wood-Gush, D.G.M. (1989). The behaviour of pigs in a semi-natural environment. - Anim. Prod. 48, p. 419-425.

Wood-Gush, D.G.M. \& Beilharz, R.G. (1983). The enrichment of a bare environment for animals in confined conditions. - Appl. Anim. Ethol. 10, p. 209-217. 